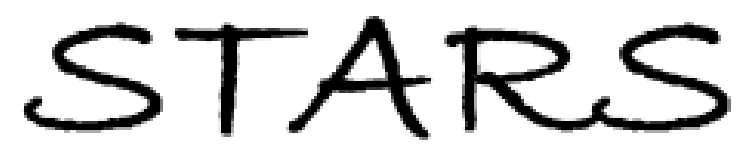

University of Central Florida

STARS

$1-1-1991$

\title{
The Fabrication Of Metal-Oxide Semiconductor Transistors Using Cerium Dioxide As A Gate Oxide Material
}

\author{
A. G. Frangoul \\ University of Central Florida \\ K. B. Sundaram \\ University of Central Florida \\ P. F. Wahid \\ University of Central Florida
}

Find similar works at: https://stars.library.ucf.edu/facultybib1990

University of Central Florida Libraries http://library.ucf.edu

This Note is brought to you for free and open access by the Faculty Bibliography at STARS. It has been accepted for inclusion in Faculty Bibliography 1990s by an authorized administrator of STARS. For more information, please contact STARS@ucf.edu.

\section{Recommended Citation}

Frangoul, A. G.; Sundaram, K. B.; and Wahid, P. F., "The Fabrication Of Metal-Oxide Semiconductor Transistors Using Cerium Dioxide As A Gate Oxide Material" (1991). Faculty Bibliography 1990s. 229. https://stars.library.ucf.edu/facultybib1990/229

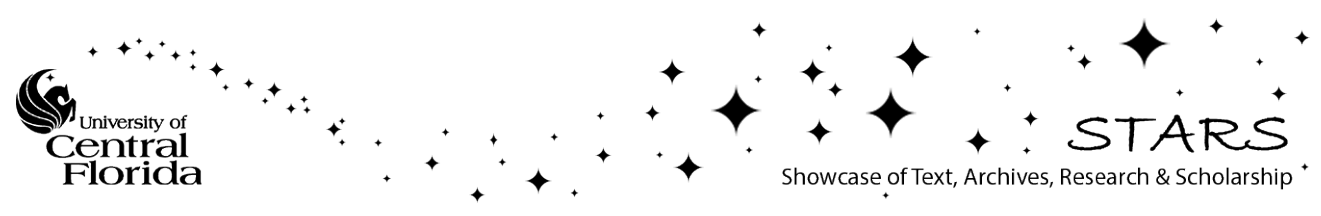




\section{The fabrication of metal-oxide-semiconductor transistors using cerium dioxide as a}

gate oxide material

A. G. Frangoul, K. B. Sundaram, and P. F. Wahid

Citation: Journal of Vacuum Science \& Technology B: Microelectronics and Nanometer Structures Processing, Measurement, and Phenomena 9, 181 (1991); doi: 10.1116/1.585285

View online: https://doi.org/10.1116/1.585285

View Table of Contents: https://avs.scitation.org/toc/jvn/9/1

Published by the American Institute of Physics

\section{ARTICLES YOU MAY BE INTERESTED IN}

Fabrication of $\mathrm{n}$-metal-oxide semiconductor field effect transistor with $\mathrm{Ta}_{2} \mathrm{O}_{5}$ gate oxide prepared by plasma enhanced metalorganic chemical vapor deposition

Journal of Vacuum Science \& Technology B: Microelectronics and Nanometer Structures Processing, Measurement, and Phenomena 12, 3006 (1994); https://doi.org/10.1116/1.587550

Fabrication of metal-oxide-semiconductor devices with extreme ultraviolet lithography

Journal of Vacuum Science \& Technology B: Microelectronics and Nanometer Structures Processing, Measurement, and Phenomena 14, 4188 (1996); https://doi.org/10.1116/1.588618

High- $\kappa$ gate dielectrics: Current status and materials properties considerations

Journal of Applied Physics 89, 5243 (2001); https://doi.org/10.1063/1.1361065

Violet/blue emission from epitaxial cerium oxide films on silicon substrates

Applied Physics Letters 70, 1647 (1997); https://doi.org/10.1063/1.118658

Erratum: Asymmetry aberrations and tolerancing of complete systems of electron lenses and deflectors [J. Vac. Sci. Technol. B 8, 1676 (1990)]

Journal of Vacuum Science \& Technology B: Microelectronics and Nanometer Structures Processing,

Measurement, and Phenomena 9, 184 (1991); https://doi.org/10.1116/1.585783

Cerium oxide nanoparticles: Size-selective formation and structure analysis

Applied Physics Letters 80, 127 (2002); https://doi.org/10.1063/1.1430502 


\title{
The fabrication of metal-oxide-semiconductor transistors using cerium dioxide as a gate oxide material
}

\author{
A. G. Frangoul, K. B. Sundaram, and P.F. Wahid \\ Depariment of Electrical Engineering, University of Central Florida, Orlando, Florida 32816
}

(Received 7 May 1990; accepted 26 October 1990)

\begin{abstract}
Cerium dioxide was employed as a gate insulator for an enhancement-type $n$-channel metaloxide-semiconductor (MOS) transistor. Cerium was evaporated in a tungsten boat and immediately oxidized for oxide uniformity. The use of $\mathrm{CeO}_{2}$ as a gate oxide in $\mathrm{MOS}$ transistor yielded a low positive threshold voltage with negligible interface charge effects. This resulted in the transistor performing as an enhancement type device.
\end{abstract}

\section{NTRODUCTION}

Research in various elemental compounds as insulating oxides has led to their potential use in thin film devices and has marked possibilities in very large scale integrated (VLSI) material technology. ${ }^{i, 2}$ Quality thin film insulating materi* als are an important factor in the design and operation of monolithic and hybrid devices. They enable device size reduction and their intrinsic dielectric properties can be used to obtain the required characteristics in various microelectronic devices. Thin films of cerium dioxide $\left(\mathrm{CeO}_{2}\right)$, a rare earth oxide, have received attention in the recent years due the high dielectric constant and the potential use of these films in thin film devices. Cerium dioxide exhibits a strong dielectric breakdown field with values on the order of $10^{7}$ $\mathrm{V} / \mathrm{cm}$. Information regarding the electrical and optical properties of $\mathrm{CeO}_{2}$ available in the literature ${ }^{3,4}$ has had infuence on its possible use in metal-oxide-semiconductor (MOS) devices. In metal-oxide-semiconductor devices, the oxide affects parameters such as the threshold voltage $\left(V_{T}\right)$ and the small signal transconductance $\left(g_{m}\right)$. For devices using thin film oxides in the range $0.02-0.2 \mu \mathrm{m}$, it becomes necessary to realize the differences that stem from the use of different types of oxides.

The threshold voltage $V_{T}$ of a MOS transistor is dependent on the type of gate oxide material used. Certain applications require not only a low value of $V_{T}$, but also a precisely controlled value to match to other devices in the circuit. Use of oxides such as $\mathrm{Si}_{3} \mathrm{~N}_{4}$ and $\mathrm{SiO}_{2}$ in devices have been reported. ${ }^{5} \mathrm{Si}_{3} \mathrm{~N}_{4}$ has a relative dielectric constant of approximately 7 compared to 3.9 of $\mathrm{SiO}_{2}$. Studies on $\mathrm{CeO}_{2}$ show that it has a relative dielectric constant of 4.2 at room temperature, which is slightly higher than $\mathrm{SiO}_{2}$. With higher relative dielectric constant materials the gate capacitance can be increased thereby reducing $V_{T}$. Even though $\mathrm{Si}_{3} \mathbb{N}_{4}$ has a high dielectric constant, it has the disadvantage of contributing charges at the oxide-nitride layer which affect $V_{T}$ directly.
This charge formation is what causes most $\mathrm{SiO}_{2}$ MOS $n$ channel enhancement devices to operate in a depletion mode. In the devices fabricated here, $\mathrm{CeO}_{2}$ is deposited on the Si substrate and there is no ionic formation due to $\mathrm{SiO}_{2}$ growth.

The application of $\mathrm{CeO}_{2}$ in $\mathrm{Al}-\mathrm{CeO}_{2}-\mathrm{Si}$ enhancementtype $n$-channel structures is investigated here. The fabrication techniques employed are filament evaporation and deposition of cerium metal $(\mathrm{Ce})$ and subsequent oxidation to get $\mathrm{CeO}_{2}$ as the gate oxide. The quality of this oxide is analyzed and directly related to the study of how it will infiuence the device characteristics and operation. In this paper, the

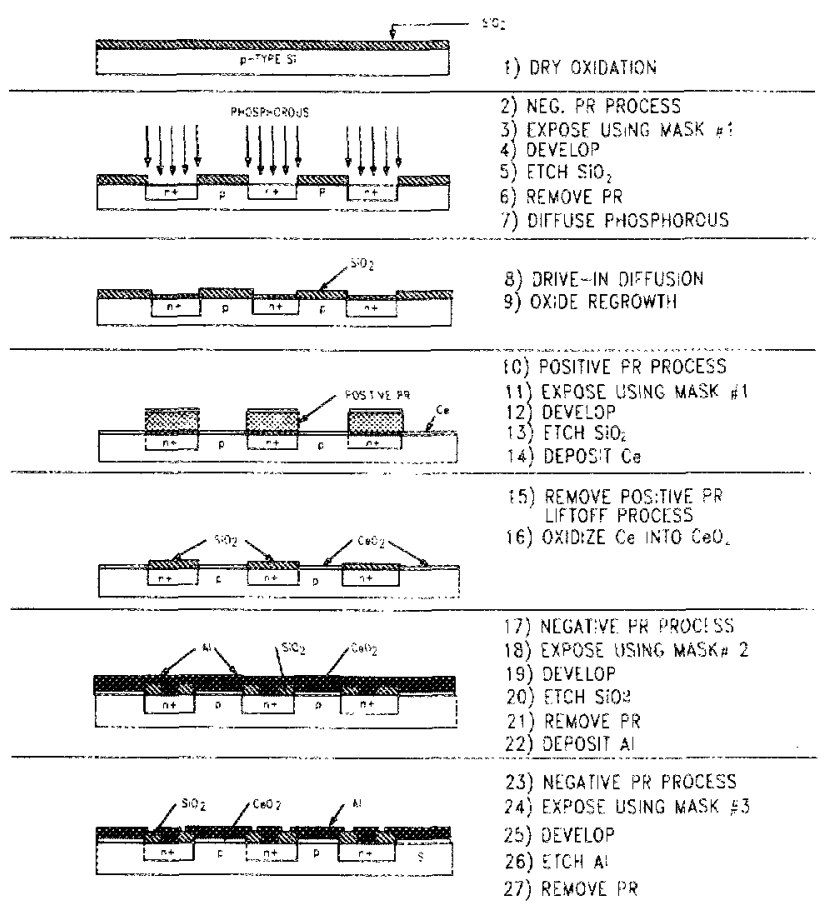

FIG. 1. Fabrication sequence for the MOS transistor. 

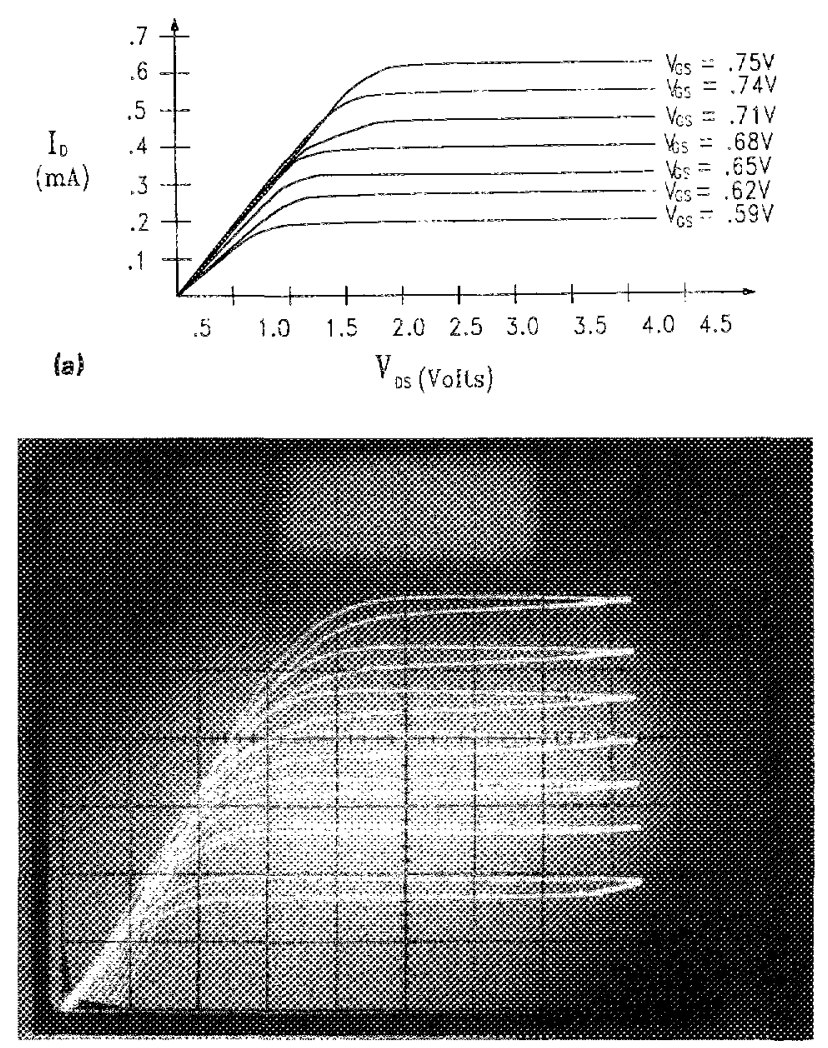

(b)

Fig. 2. (a) Plot of $I_{D}$ vs $V_{\text {DS }}$ (b) Photograph of the $I_{D}$ vs $V_{\text {Ds }}$ curve.

effect of $\mathrm{CeO}_{2}$ on the MOS threshold voltage and the gate capacitance are reported.

\section{EXPERIMENTAL}

The device was fabricated on a 2 in. $p$-type Si wafer with a $\langle 100\rangle$ orientation and a resistivity between $8-15 \Omega \mathrm{cm}$. The substrate was cleaned with trichloroethylene, acetone, methanol and deionized water with a resistivity of 17.7 $M \Omega \mathrm{cm}$. The wafer was then placed in sulfuric peroxide cleaner following a "hot etch" $\left(6 \mathrm{NH}_{4} \mathrm{~F}: 1 \mathrm{HF}\right)$. After proper masking sequences, the source and drain regions were opened for the predeposition of phosphorous. Solid solubility concentration was achieved in a diffusion furnace at $900^{\circ} \mathrm{C}$ for $20 \mathrm{~min}$. This was followed by a drive-in step, a dry-wet-dry oxidation sequence, each of 10 min duration, at $1100^{\circ} \mathrm{C}$. The carrier gas for dry oxidation was oxygen and nitrogen was used for the wet oxidation. A second masking sequence for the gate region was performed, wherein the area over which $\mathrm{CeO}_{2}$ was to be deposited was etched thoroughly of $\mathrm{SiO}_{2}$ in a hot etch solution. Ce was then deposited by filament evaporation using a tungsten boat in a cryogenic pump vacuum system. Approximately $70 \mathrm{mg}$ of Ce was evaporated on the wafer in a vacuum of $1 \times 10^{-5}$ Torr. Several thickness measurements were made over the 2 in. diam $\$$ wafer using an optica! interferometer. The measurements resulted in thickness variations of $+100 \AA$. The wafer was placed at a distance of $20 \mathrm{~cm}$ from the filament evaporator using a glass chimney. Ce deposited on areas other than the gate region was removed by a lift-off process. The wafer was then placed in a dry oxidation furnace and the complete oxidation of the cerium film was achieved in $10 \mathrm{~min}$ at $400^{\circ} \mathrm{C}$


(b)

FIG. 3. (a) Plot of $I_{D}^{1 / 2}$ vs $V_{G S}$. (b) Photograph of $I_{D}$ vs $V_{G s}$.

with a constant flow of $\mathrm{O}_{2}$. The oxidation uniformity was excellent, as indicated by optical measurements done on these films. A third masking step was performed on the source and drain for the opening of the contact windows. Aluminum was then deposited by thermal evaporation in the cyro pumped vacuum system. The fourth masking step was done to define the contacts, where $A 1$ was etched in a solution of phosphoric acid and deionized water (one part phosphoric to three parts deionized water) and heated to about $90^{\circ} \mathrm{C}$. The $\mathrm{Al}$ etchant does not attack $\mathrm{CeO}_{2}$ as it can be etched only by buffered hydrofuoric acid. Figure 1 outlines the fabrication process employed.

\section{HE. RESULTS}

The $\mathrm{CeO}_{2} n$-type enhancement MOS transistors were fabricated with a gate oxide thickness of $0.16 \mu \mathrm{m}$ on a silicon substrate with a $\langle 100\rangle$ orientation. The gate width was $200 \mu \mathrm{m}$.

A HP177 curve tracer was used to measure the characteristics of the devices. Figure 2 (a) shows typical characteristic curves. These curves were redrawn, for clarity, from the photographs shown in Fig. 2(b) taken from the curve tracer. Figure 3 (a) shows the square root of the drain current versus the gate voltage redrawn from photographs shown in Fig. 3 (b). The threshold voltage determined from this graph shows a value of approximately $0.3 \mathrm{~V}$. This value is representative of a number of samples measured on a typical $2 \mathrm{~cm} \times 2$ $\mathrm{cm}$ Si substrate. A MOS device with a $\mathrm{SiO}_{2}$ gate of thickness 
$0.16 \mu \mathrm{m}$ grown on a (100) substrate orientation has a threshold voltage of approximately $-2.4 \mathrm{~V}$. Such a large negative threshold voltage can only be attributed to sodium contamination introduced during the fabrication of the device. Both the $\mathrm{CeO}_{2}$ and $\mathrm{SiO}_{2}$ gate cevices were fabricated under the same processing conditions, but the effect of oxide charges was less dramatic in $\mathrm{CeO}_{2}$ than in $\mathrm{SiO}_{2}$. The interface charges for both the $\mathrm{CeO}_{2}$ and the $\mathrm{SiO}_{2}$ gate MOS devices were calculated using the measured threshold voltages. The $\mathrm{SiO}_{2}$ gate MOS device yielded an interface charge of $3.8 \times 10^{11} \mathrm{q} \mathrm{C} / \mathrm{cm}^{2}$ with $V_{T}=-2.4 \mathrm{~V}$. With the $\mathrm{CeO}_{2}$ gate, the interface charge was $1.5 \times 10^{10} \mathrm{q} \mathrm{C} / \mathrm{cm}^{2}$ with $V_{T}=0.3 \mathrm{~V}$. For the $\mathrm{SiO}_{2}$ gate the device is on for zero gate voltage. The normally on effect in the $n$-type enhancement device using $\mathrm{SiO}_{2}$ is a problem that is dealt with by special fabrication methods. Ion implantation is usually required to adjust the threshold voltage to positive values. $\mathrm{CeO}_{2}$ does not present this problem and hence does not require an additional processing step for charge reduction.

The transconductance of the device biased at $0.4 \mathrm{~mA}$ is approximately $2 \mathrm{~mA} / \mathrm{V}$ as obtained from the $I_{0}$ versus $V_{\mathrm{GS}}$ curve. This is typical of most MOS devices.

'Y. Nishioka, H. Shinriki, and K. Mukai, J. Electrochem. Soc. 136, 872 (1989).

${ }^{2}$ Z. T. Al-Dhhan and C. A. Hogarth, Int. J. Electron. 63, 573 (1987).

${ }^{3}$ Z. T. Al-Dhhan and C. A. Hogarth, Phys. Status Solidi B 137, k157 (1986).

${ }^{4}$ S. Mochizuki, Phys. Status Solidi B 114, 189 (1982).

${ }^{5}$ B. Streetman, Solid State Electronic Devices, 2nd ed. (Prentice-Hall, Englewood Cliffs, NJ, 1990), Chap. 8. 